\title{
Acoustic Emission Characteristics and Failure Prediction of the Granite with Orthogonal Cracks under Compressive Loading
}

\author{
Yizhong $J u^{1}$ and $\mathrm{Xu} \mathrm{Wu} \mathbb{D}^{2}$ \\ ${ }^{1}$ Department of Science and Engineering, Tongcheng Teachers College, Tongcheng 231400, China \\ ${ }^{2}$ Beijing Municipal Engineering Research Institute, Beijing 100037, China \\ Correspondence should be addressed to Xu Wu; 13051510807@163.com
}

Received 26 August 2020; Revised 21 September 2020; Accepted 11 October 2020; Published 22 October 2020

Academic Editor: Xun Xi

Copyright ( $) 2020$ Yizhong Ju and Xu Wu. This is an open access article distributed under the Creative Commons Attribution License, which permits unrestricted use, distribution, and reproduction in any medium, provided the original work is properly cited.

\begin{abstract}
Natural joints existing in rock significantly affect the stability of long-term served subsurface engineering. In this paper, granite specimens with two orthogonal cracks were made for uniaxial compressive tests. The acoustic emission monitoring (AE) and digital image correlation techniques were employed to record the acoustic events and cracking of rock. The stress, ring-down count, and cumulative ring-down count of $\mathrm{AE}$ during the tests were obtained. The $b$-value of $\mathrm{AE}$ was calculated based on the magnitude and number of AE events. The relationship between the $b$-value and rock cracking for the specimens with orthogonal cracks was discussed. Further, the effects of orthogonal cracks distribution on the $b$-value and rock cracking were investigated. Experimental results show that the specimens with orthogonal cracks would undergo multiple cycles of energy accumulationrelease-reaccumulation-rerelease under the uniaxial compression. For the specimens with orthogonal cracks, the $b$-value of AE was volatile but generally decreased until complete failure. Every cracking event during the loading made the $b$-value drop and then the reaccumulation of energy made the $b$-value increase or stable. The specimen with orthogonal cracks was more prone to initial cracking than the intact rock. The orientation of cracks had effects on the $b$-value evolution and crack patterns. The $b$-value reaching about 1.5 can be used as the failure precursor of specimens with orthogonal cracks.
\end{abstract}

\section{Introduction}

For long-term served subsurface engineering, the failure of rock mass could lead to serious defects or accidents like the large deformation, roof falling, and leakage [1-3]. The natural rock mass contains numerous weak structural planes (i.e., joints or fissures) which significantly affect mechanical behaviors of the rock mass. The orthogonal joint is one of the most common joint geometries in the natural rock mass, which are generated by geotectonic movements [4]. It is of great significance to investigate the failure characteristics of rocks with orthogonal joints through comprehensive experiments for predicting rock failure and ensuring the stability of rock engineering.

In the past decades, considerable research has been carried out on the failure of jointed rocks or synthetic rock materials induced by external loads [5-15]. Lee and Jeon [5] made granite specimens with precracks of $1 \mathrm{~mm}$ thickness and found that the wing and secondary cracks occurred under the compressive loading. Bobet and Einstein [6] employed gypsum specimens with cracks to represent jointed rocks and carried out uniaxial and biaxial compression tests on the specimens with two preexisting parallel joints. Yang et al. $[7,8]$ carried out a series of compression tests of precracked sandstone specimens and they found that the failure of rock was determined by the crack initiation, growth, and interaction around the preexisting cracks. Xi et al. [12] investigated the failure of granite with a preexisting crack and found that the angle between preexisting crack and loading direction had significant effects on the compressive strength and crack propagation speed. Although the effects of preexisting cracks on the rock compressive strength and crack patterns had been widely studied, the timely failure or cracking characteristics of rocks with 


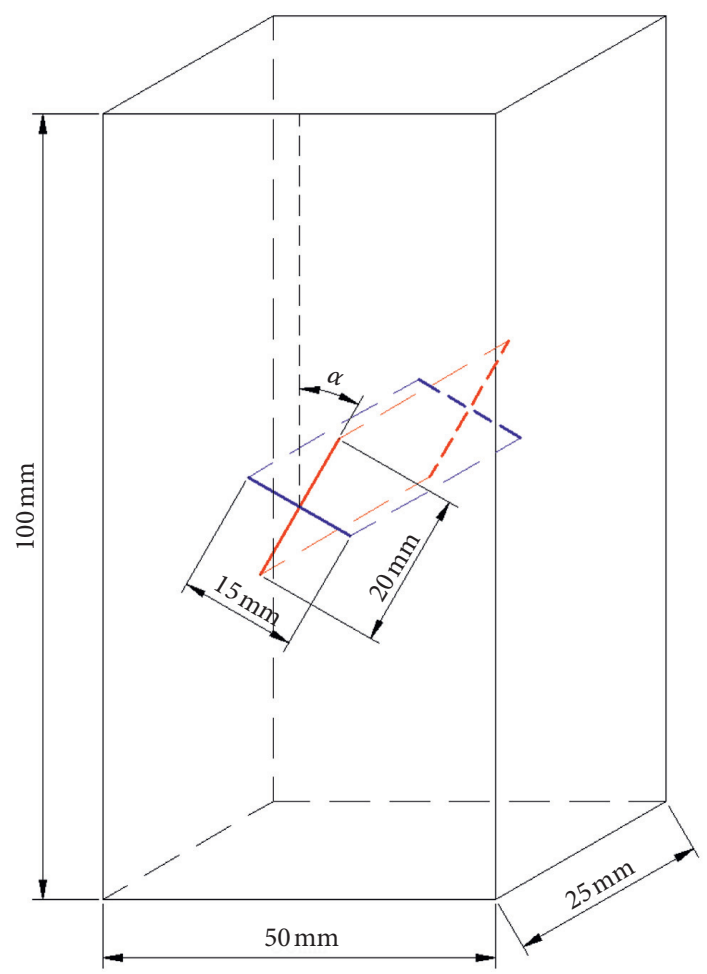

FIGURE 1: The location and geometry of the preexisting orthogonal cracks.

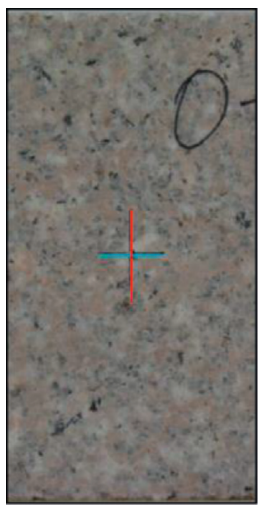

(a)

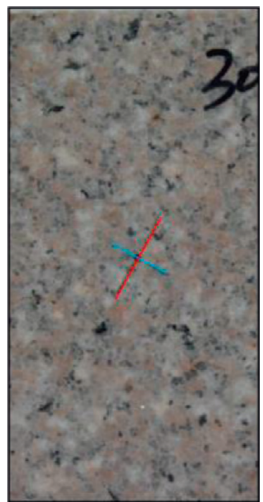

(b)

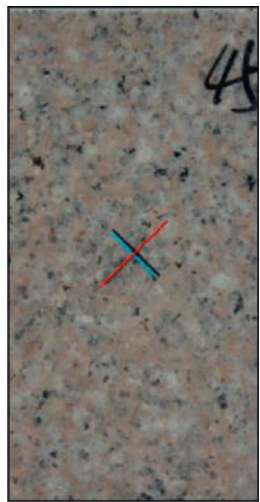

(c)

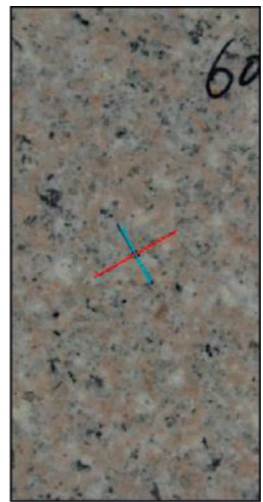

(d)

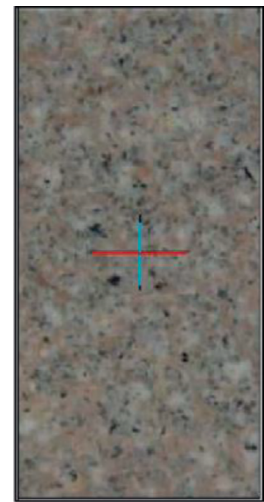

(e)

FigURE 2: The granite specimens with two orthogonal cracks: (a) $\alpha=0^{\circ} 00-90$, (b) $\alpha=30^{\circ} 30-90$, (c) $\alpha=45^{\circ} 45-90$, (d) $\alpha=60^{\circ} 60-90$, and (e) $\alpha=90^{\circ}$ 90-90.

preexisting cracks during the compression tests are not clear. And it is much difficult to predict the failure of jointed rocks without understanding the timely cracking characteristics and failure precursor. Moreover, existing experimental results on the failure of specimens with orthogonal cracks are limited.

Acoustic emission (AE) can be defined as transient elastic stress waves produced by a release of energy from a localized source, which can also be thought of as tiny quakes that occur in solids [16]. AE testing or monitoring techniques have been widely employed to investigate the propagation of defects in brittle materials, such as rocks.
The AE parameters and waves can reflect the timely failure process of rock under external loads. With the development of $\mathrm{AE}$ monitoring techniques, some researchers [17-26] have proposed many AE parameters or indexes for analyzing the failure process of rock, for example, $\mathrm{AE}$ counts, amplitude, $b$-value, average frequency, and duration. Ganne et al. [17] divided the accumulated AE activities into four stages, which correspond to the generation, propagation, coalescence, and final failure of microcracks, respectively. Eberhardt et al. [18] monitored the $\mathrm{AE}$ events of granite under compressive tests and found that the AE wave significantly changed after 


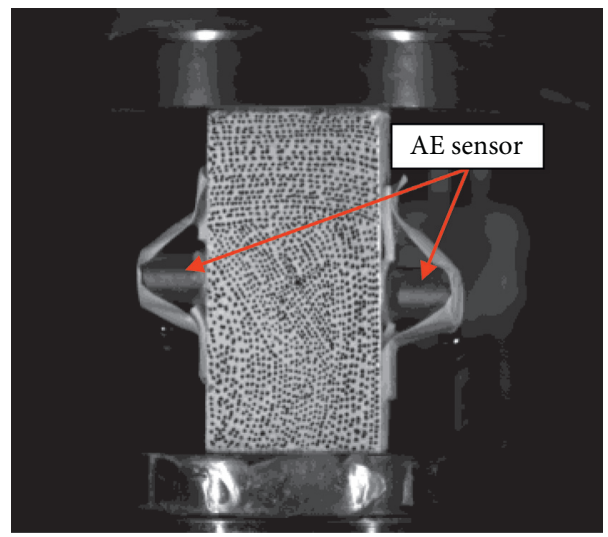

FIgURE 3: The layout of loading and AE sensors.

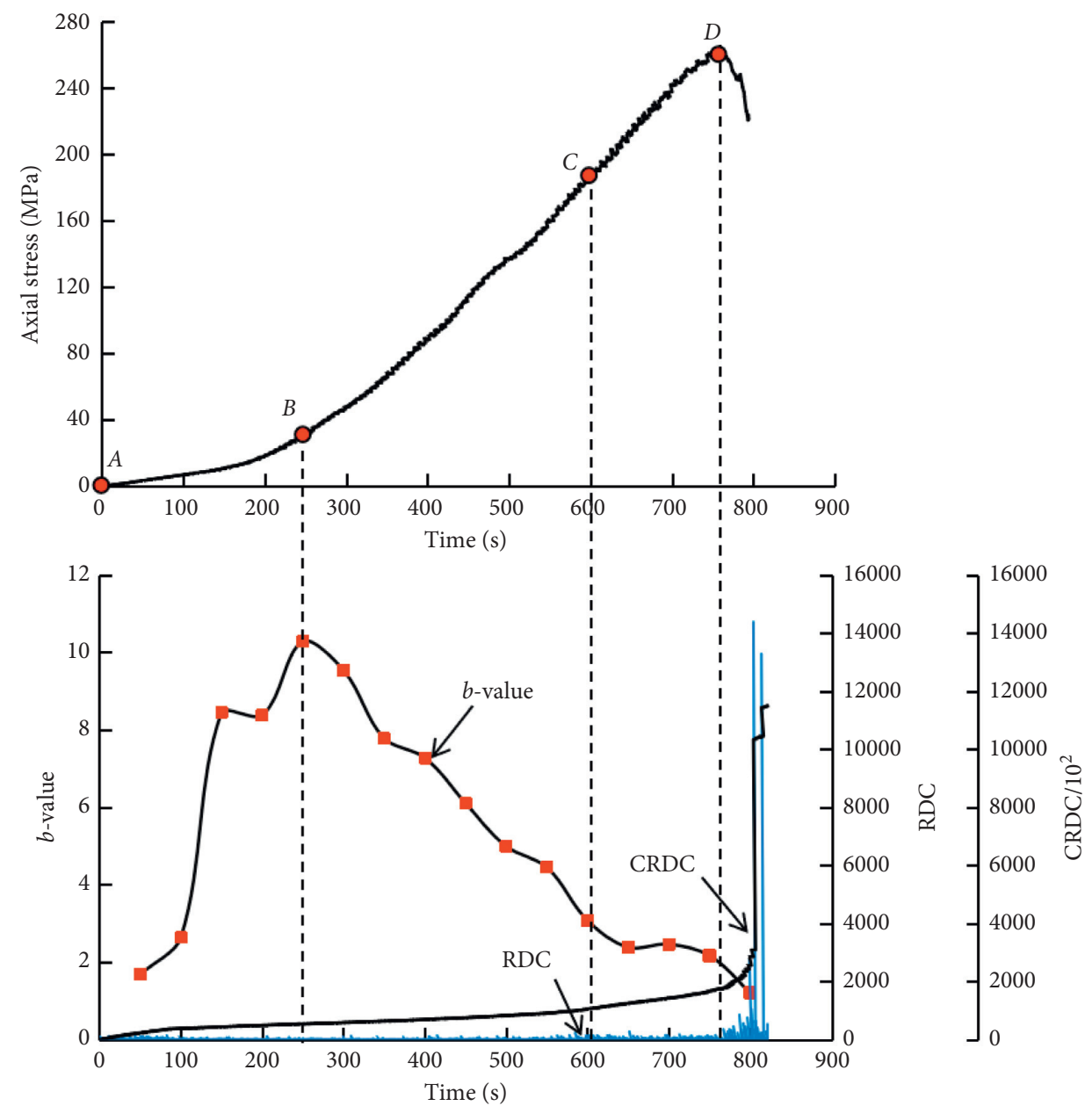

FIgURE 4: The evolutions of stress, $b$-value, RDC, and CRDC of AE with time for the intact rock.

cracking. Zhang et al. [19] carried out the AE monitoring of granite under uniaxial compression and found that there is a relatively "quiet" period for AE events before rock failure. Recently, some researchers tried to use the well-known $G-R$ earthquake equation to calculate the $b$ value by $\mathrm{AE}$ counts and found the $b$-value was closely related to the failure of rock. Zhao et al. [20] investigated the failure of intact dacite specimens under compressive loading and found that the rapid decrease of the $b$-value can be the failure precursor of rock. Li et al. [21] found the $b$-value and fractal dimension of AE from the uniaxial compression tests can be the failure precursor of granite. Amongst the existing research on the $\mathrm{AE}$ characteristics and failure precursor of rock, most were focused on the 


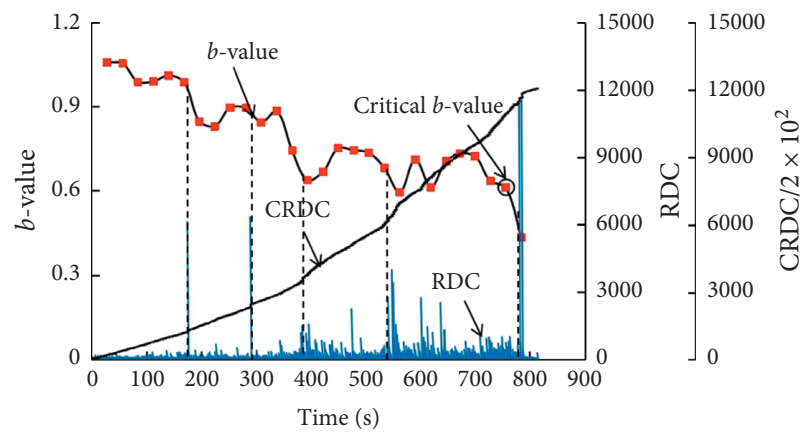

(a)

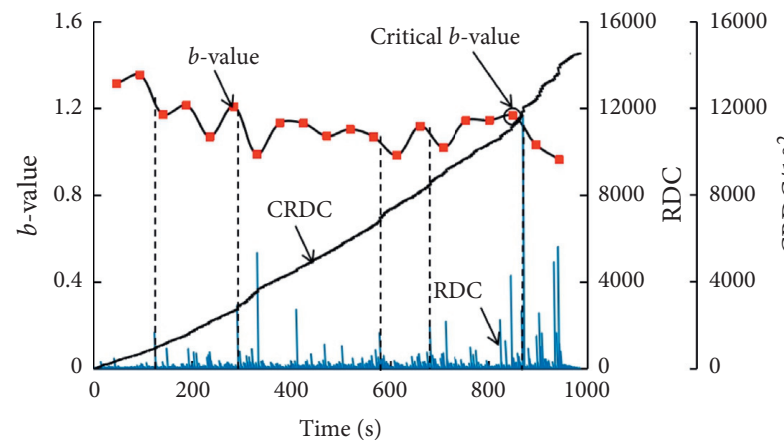

(c)

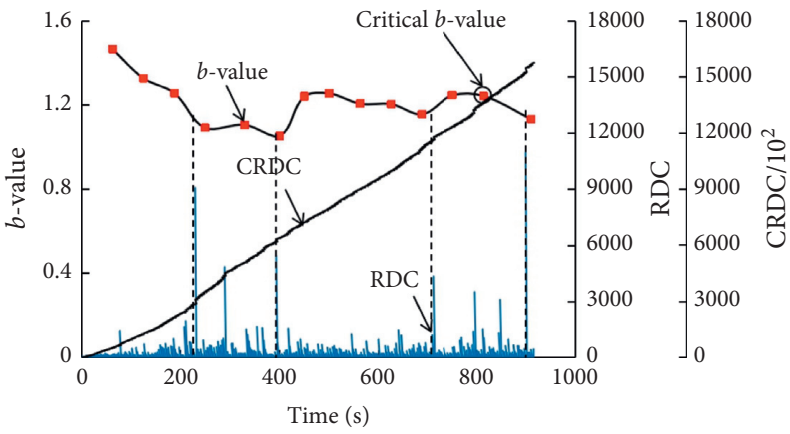

(b)

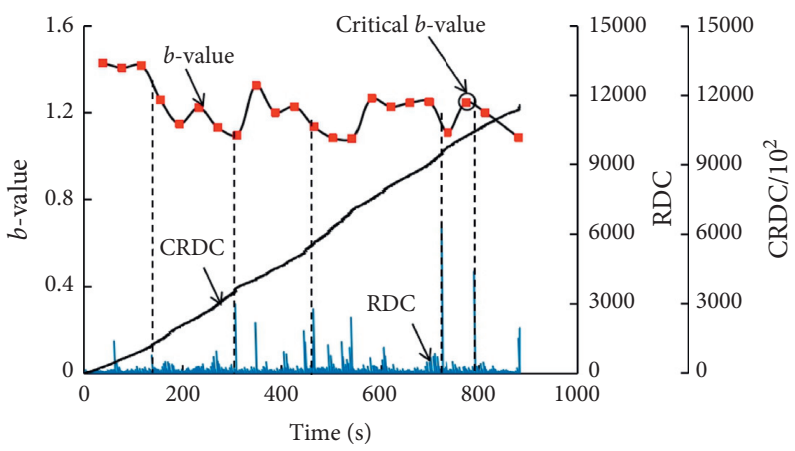

(d)

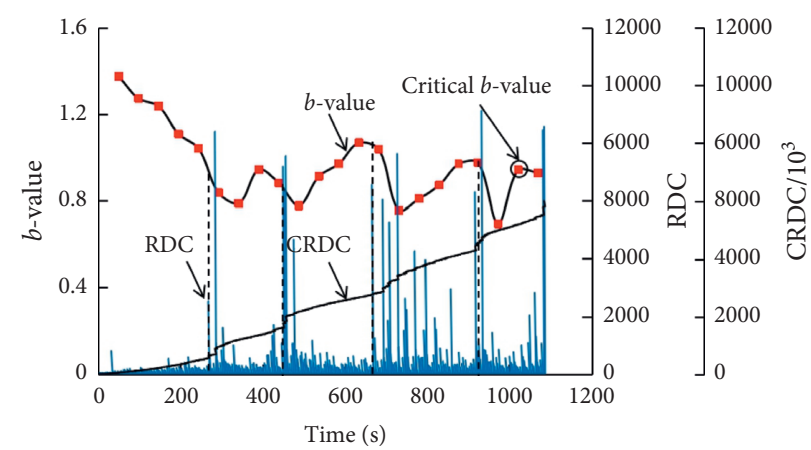

(e)

FIgURE 5: The evolutions of $b$-value, ring-down count, and cumulative ring-down count of AE with time for the specimens with orthogonal cracks. (a) 00-90. (b) 30-90. (c) 45-90. (d) 60-90. (e) 90-90.

TABle 1: The maximum $b$-value.

\begin{tabular}{lccccc}
\hline $\begin{array}{l}\text { Intact specimen } \\
\text { Maximum } b \text {-value }\end{array}$ & \multicolumn{5}{c}{ Specimens with orthogonal cracks } \\
I & $00-90$ & $30-90$ & $45-90$ & $60-90$ & $90-90$ \\
\hline 10.29 & 1.06 & 1.47 & 1.36 & 1.43 & 1.38 \\
\hline
\end{tabular}

failure of intact rock specimens while the $b$-value of AE for granite with orthogonal cracks has never been studied.

This paper attempts to investigate the acoustic emission characteristics and failure prediction of the granite with orthogonal cracks by comprehensive experiments. The granite taken from a deep gold mine is made into cubic specimens with dimensions of $50 \mathrm{~mm} \times 25 \mathrm{~mm} \times 100 \mathrm{~mm}$. The water cutter techniques are used for making two orthogonal cracks with $0.3 \mathrm{~mm}$ thickness in the center of the specimens. The uniaxial compression tests are carried out on the intact specimens and precracked specimens. During the compressive loading, the $\mathrm{AE}$ events are monitored for recording the cracking of rock. Further, the stress, $b$-value, ring-down count (RDC), and cumulative ring-down count (CRDC) of AE during the tests are obtained. The cracking process and crack patterns are recorded by a digital image correlation (DIC) system. The relationships between the $b$-value and rock cracking are analyzed and discussed. Finally, the effects of the preexisting crack angle on the $b$-value evolution and crack patterns are investigated.

\section{Methodology}

2.1. Specimen and Experiments. Unlike the previous studies which made rock-like specimens with preexisting cracks by inserting metallic sheets into cement-based materials 


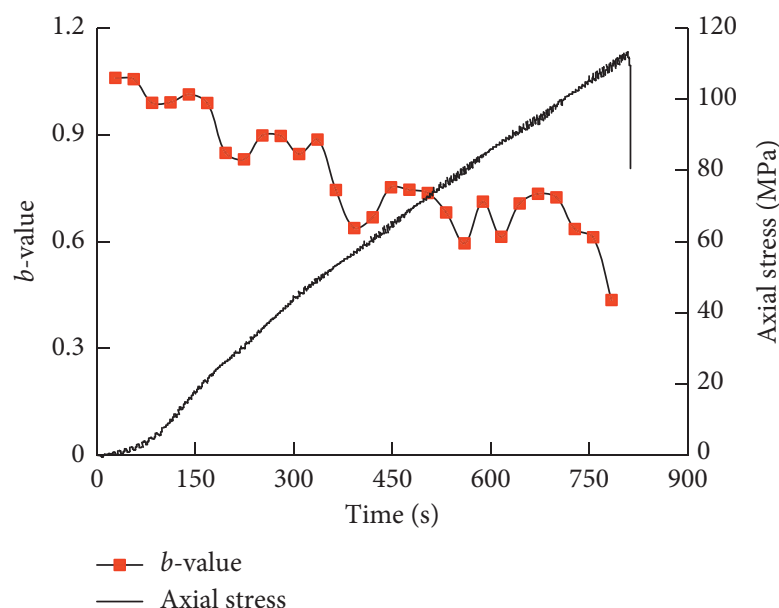

(a)

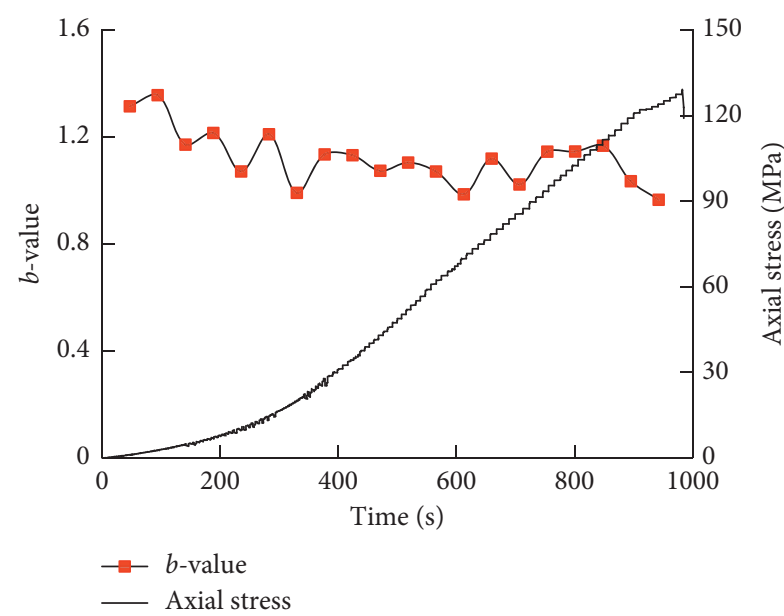

(c)

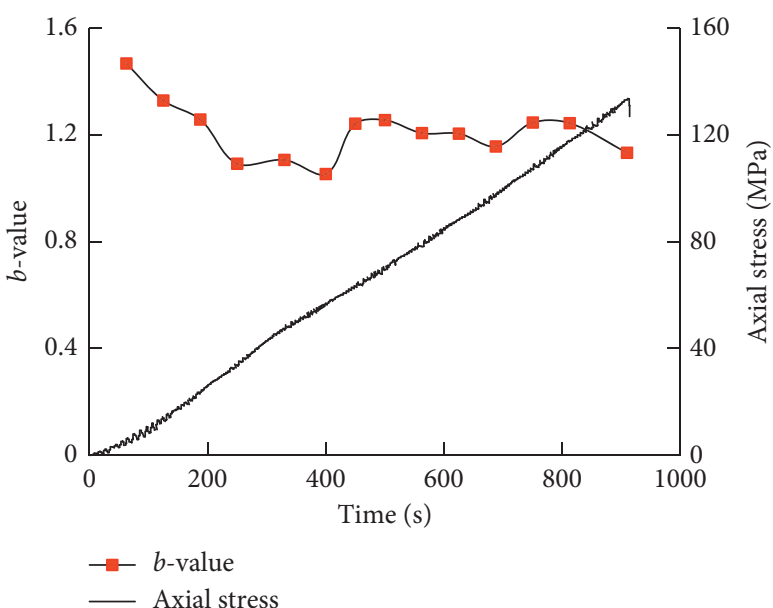

(b)

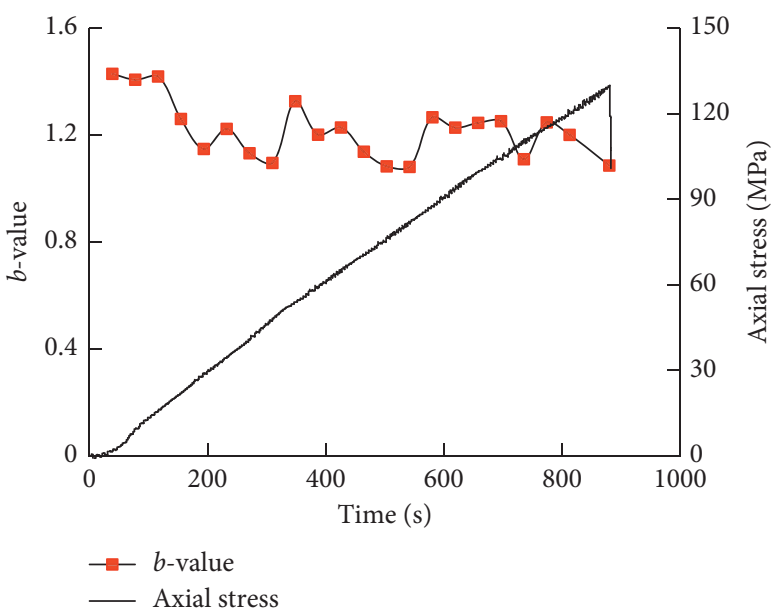

(d)

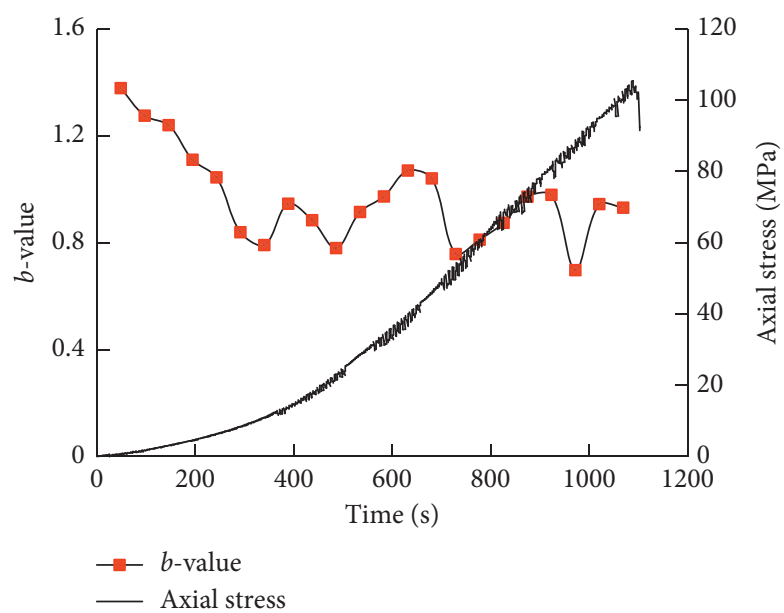

(e)

Figure 6: The evolutions of the axial stress and $b$-value with time for the specimens with orthogonal cracks. (a) 00-90 (b) 30-90 (c) 45-90. (d) 60-90. (e) 90-90.

[27-30], we employed in situ rock and made nonpersistent joints by water-cutting techniques. The granite was taken from a deep gold mine with excavation depth over $-1000 \mathrm{~m}$. The specimens were made as cubic with the dimensions of $50 \mathrm{~mm}$ in length, $25 \mathrm{~mm}$ in width, and $100 \mathrm{~mm}$ in height. Two orthogonal cracks were made in the center of the specimens. The dimensions for the main crack and secondary crack were designed as 


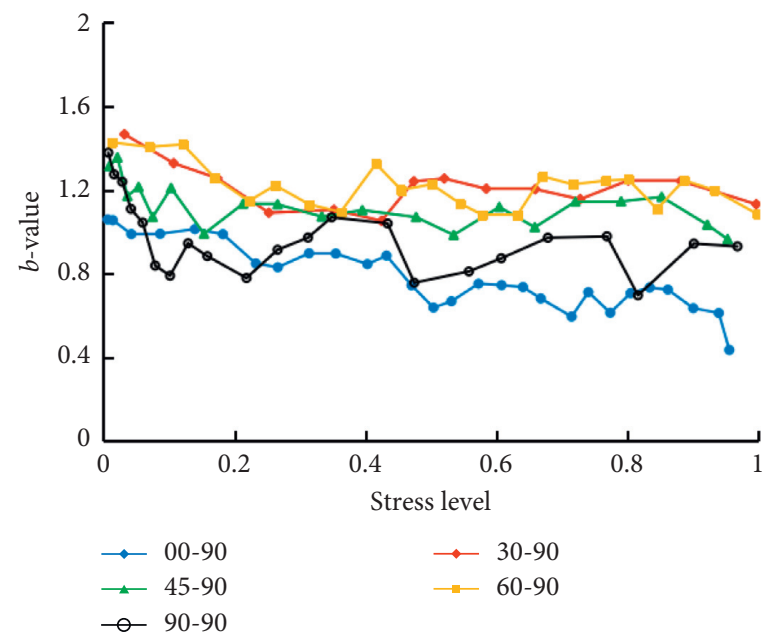

Figure 7: The relationship between the $b$-value of $\mathrm{AE}$ and the stress level for the specimens with orthogonal cracks.

TABLE 2: The critical $b$-values of $\mathrm{AE}$ and the corresponding stress level.

\begin{tabular}{lcc}
\hline Specimen & $b_{c}$ & Corresponding stress level \\
\hline $00-90$ & 0.64 & 0.94 \\
$30-90$ & 1.24 & 0.88 \\
$45-90$ & 1.17 & 0.85 \\
$60-90$ & 1.25 & 0.88 \\
$90-90$ & 0.94 & 0.90 \\
\hline
\end{tabular}

$25 \mathrm{~mm} \times 0.3 \mathrm{~mm} \times 20 \mathrm{~mm}$ and $25 \mathrm{~mm} \times 0.3 \mathrm{~mm} \times 15 \mathrm{~mm}$, respectively. Figure 1 illustrates the location and geometry of the preexisting main crack (in red line) and secondary crack (in blue line). The thickness of the cracks is just $0.3 \mathrm{~mm}$ which is very thin for replacing real joints. $\alpha$ is the angle between the main crack and loading direction. To investigate the effect of the main crack direction on rock failure, the angle $\alpha$ of the specimens is set as $0^{\circ}, 30^{\circ}, 45^{\circ}$, $60^{\circ}$, and $90^{\circ}$, respectively. The secondary crack is always perpendicular to the main crack. Figure 2 shows the final specimens with their names.

The uniaxial compressive tests were carried out by the GAW-2000 rigid mechanical machine. The loading was controlled by the displacement and the loading speed is $0.03 \mathrm{~mm} / \mathrm{min}$. The AE events were monitored and recorded by PCI-2 AE system with the threshold value of acoustic emission being $40 \mathrm{~dB}$. The sampling frequency range of the $\mathrm{AE}$ sensor is $1 \mathrm{kHz} 3 \mathrm{MHz}$, and the $\mathrm{A} / \mathrm{D}$ conversion resolution is 18 bits. The $\mathrm{AE}$ system can perform real-time or postdata analysis and spectrum analysis. Figure 3 shows the loading and monitoring layout. The VIC-3D noncontact strain field measurement system was adopted, which included DIC digital image correlation analysis software, image acquisition equipment, lighting equipment, calibration and optical distortion correction system, supporting positioning, and other auxiliary equipment. The displacement and strain data of the samples were recorded during the loading processes.
2.2. b-Value of AE Results and Its Calculation. In 1956, Gutenberg and Richter proposed an equation to express the relation between earthquake magnitude and frequency $[31,32]$. The famous $G-R$ law is expressed as follows:

$$
\lg N=a-b M
$$

where $N$ is the number of seismic events having a magnitude larger than M. $a$ and $b$ are fitting parameters. The parameter $b$ is commonly called the $b$-value which has been widely studied for revealing the occurrences of earthquakes.

The brittle failure of rock has similarities with the earthquake. Therefore, rock researchers attempted to analyze the $b$-value by the G-R law for the relationship between the magnitude and frequency of AE events [19-21]. And some interesting findings have been obtained through experiments on intact rock specimens. We attempted to investigate the $b$-value development for rock specimens with two orthogonal cracks. The $b$-value can be calculated as follows [21]:

$$
b=\frac{n \lg e}{\sum_{1}^{n} \lg A_{\mathrm{i}}-n \lg A_{\min }},
$$

where $A$ is the magnitude of the $\mathrm{AE}$ events; $A_{\min }$ is the smallest magnitude in one catalogue of AE; $n$ is the total number of the $\mathrm{AE}$ events in one catalogue.

\section{Experimental Results}

3.1. Intact Specimen. The uniaxial compressive test on an intact granite specimen without preexisting cracks was first carried out for comparisons. The axial force from the mechanical machine and the AE events were simultaneously recorded during the tests. Further, the axial stress was obtained by dividing the axial force by the cross section area of the specimens. Figure 4 shows the evolutions of axial stress, $b$-value, ring-down count (RDC) of $\mathrm{AE}$, and cumulative ring-down count (CRDC) of $\mathrm{AE}$ with time increasing. It can be seen that there are four stages for the stress evolution. In stage I, the axial stress slowly nonlinearly increased which 


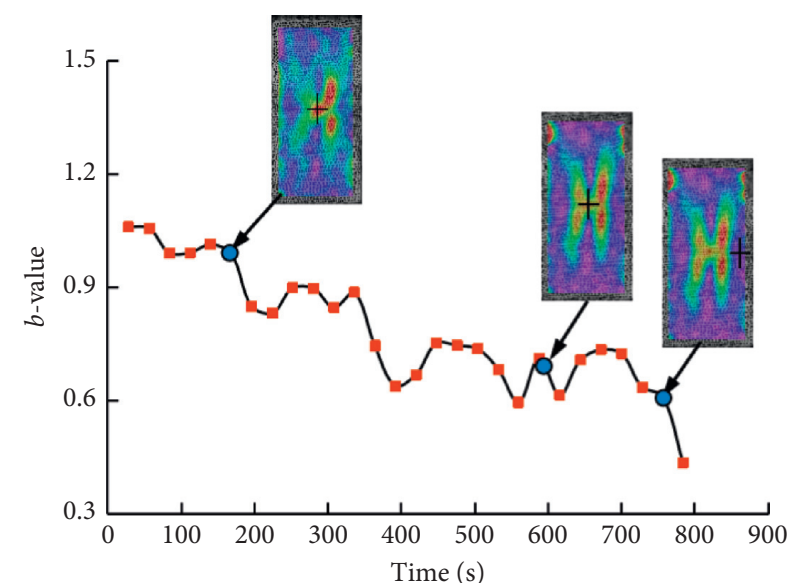

(a)

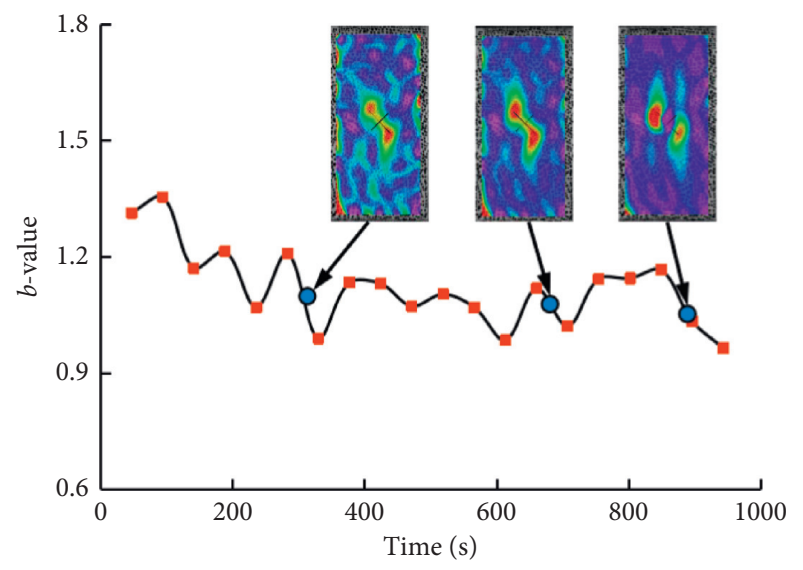

(c)

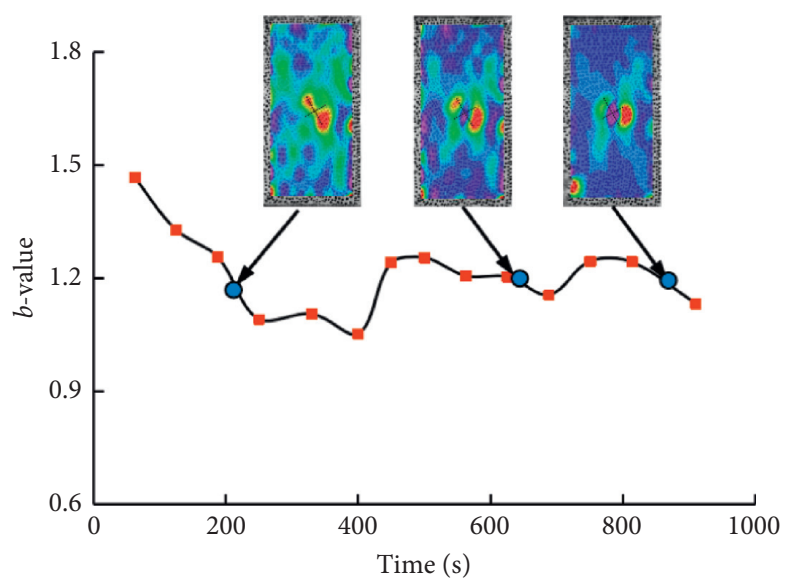

(b)

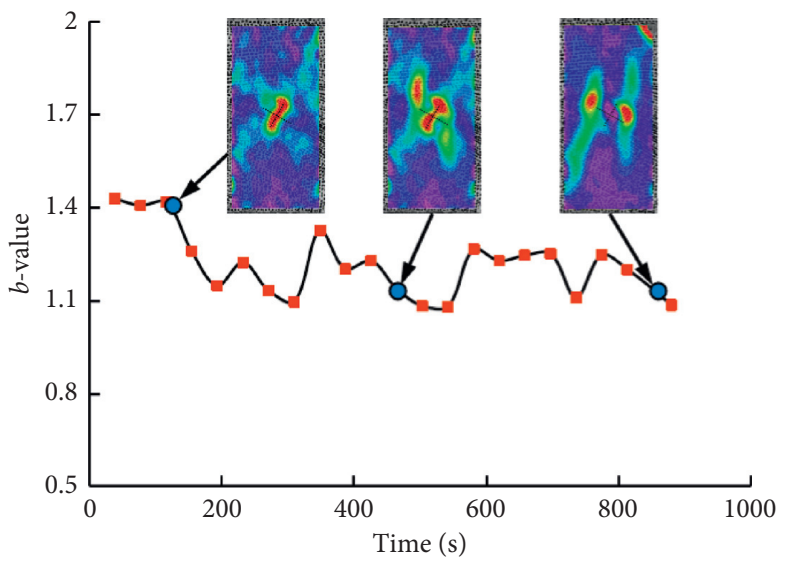

(d)

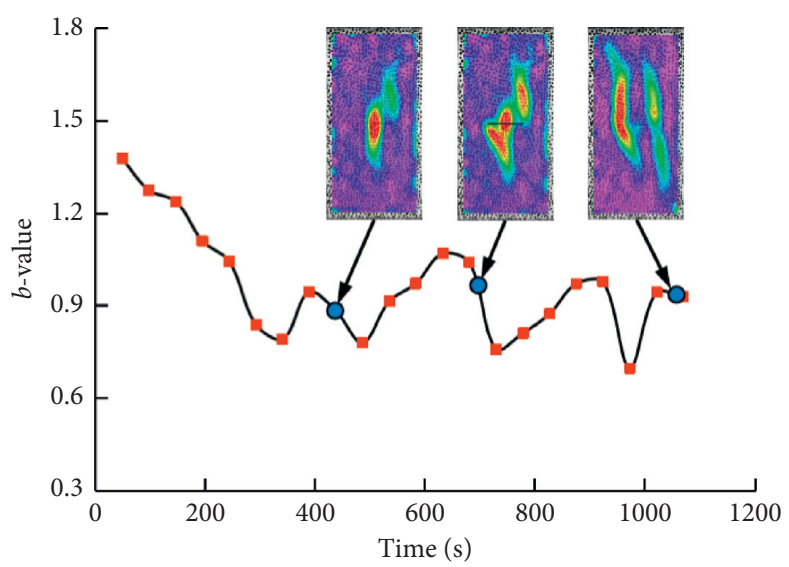

(e)

FiguRE 8: Cracking processes and $b$-value evolutions with time for the specimens with orthogonal cracks. (a) 00-90 (b) 30-90 (c) 45-90. (d) 60-90. (e) 90-90.

indicated the clamping and sealing phase $(\mathrm{AB})$. In stage II, the axial stress was close to linearly increasing which indicated the linear deformation of rock (BC). In stage III, the stress fluctuation increased which indicated microcracks initiation (CD).. In stage IV, the stress began to decrease until complete failure (after D). The $b$-value gradually increased to a peak value of about 10 at the end of stage I and then almost linearly decreased until the end of stage II. In the unstable stress increasing stage (Stage III), the $b$-value firstly increased and then decreased with time. After that, the $b$ value dropped to about 1 when rock failure occurs. The RDC suddenly increased at the postpeak stage and the CRDC exponentially increased. It can be concluded that the $b$-value is closely related to the rock stress evolution and rock failure. 
The peak of the $b$-value occurs when rock is loaded for clamping and sealing. And with the elastic deformation and microcracks initiation, the $b$-value is generally decreasing. The smaller the value $b$, the more likely the rock to fail.

3.2. Specimen with Orthogonal Cracks. Figure 5 illustrates the evolutions of the $b$-value, ring-down count (RDC) of AE, and cumulative ring-down count (CRDC) of AE with time increasing for the specimens with two orthogonal cracks. It can be found that, for the specimens with orthogonal cracks, the RDC of AE discretely suddenly increased during the loading and the CRDC of AE gradually rose. The AE can be classified as a quiet period and outbreak period during the compression tests. This phenomenon indicated that the specimens with orthogonal cracks stepwise cracked with the axial load increasing. The jointed specimen would undergo multiple cycles of energy accumulation-release-reaccumulation-rerelease under the uniaxial compression.

For the specimens with two orthogonal cracks, the $b$ value was volatile but generally decreased until complete failure. The number of $b$-values for the specimens with different main crack angle $\alpha$ is different. It is interesting to find that, during the outbreak period of $\mathrm{AE}$ ring-down count, the $b$-value generally dropped while, during the quiet period, the $b$-value was stable or increased. Therefore, for the specimens with two orthogonal cracks, every cracking event during the loading will make the $b$-value drop and then the reaccumulation of energy makes the $b$-value increase or stable.

\section{Analysis and Discussion}

The maximum $b$-value can reflect the energy storage capability for rock. The maximum $b$-value for the intact specimen and the precracked specimens is listed in Table 1. It can be seen that the maximum $b$-value for the intact specimen was 10.29 which was significantly larger than that for the specimens with two orthogonal cracks. Therefore, the intact can stably absorb elastic deformation energy from the external loads before rock crack initiation. However, the $b$ values for the specimens with orthogonal cracks were in the range of 1.3-1.5 except for the specimens with the main crack parallel to the loading direction (i.e., specimen 00-90). The maximum $b$-value occurred at the beginning stages of loading. Therefore, the specimen with orthogonal cracks is more prone to initial cracking than the intact rock.

The dropping times of the $b$-value can be regarded as the times of cracking events during the compression test. It can be seen in Figure 5 that there were 3-6 troughs in the $b$-value curves for the specimens with orthogonal cracks, which indicated the specimens experienced significant cracking for 3-6 times before complete failure. The critical $b$-value defined as the $b$-value beginning to drop just before rock failure was introduced to discuss the failure characteristics. As shown in Figure 5, the critical $b$-values were about 0.63-1.24. Therefore, the orientation of cracks has effects on the critical $b$-value. The $b$-value reaching about 1.5 can be used as the failure precursor of specimens with orthogonal cracks. The minimum critical $b$-value occurred for the 00-90 specimens. Therefore, when the joints or fissures are parallel to the loading direction, the $b$-value for failure precursor is smaller.

The stress and strength during the uniaxial compression test may be also related to the $b$-value. Figure 6 shows the $b$ value and axial stress evolution with time increasing. The uniaxial compressive strengths for the specimens with 00-90, 30-90, 45-90, 60-90, and 90-90 were 113.32, 133.56, $129.14,129.87$, and $105.44 \mathrm{MPa}$, respectively. With the angle $\alpha$ between the main crack and loading direction increasing, the uniaxial compressive strength firstly increased and then decreased. The minimum uniaxial compressive strength occurred for the specimen with the main crack angle of $90^{\circ}$. For the specimens with orthogonal cracks, the axial stress gradually increased until rock failure.

Although the $b$-value was fluctuating, the stress kept increasing. Taking specimen $00-90$ as an example, at the first loading stage, the clamping and sealing of rock occurred. Compared with the intact specimen, the clamping and sealing phase was shorter and the $b$-value was relatively stable. At the elastic stage, the $b$-value experienced the cycles of "dropping, increasing, being stable, and redropping." The $b$-value rapidly decreased to the minimum value when rock complete failure occurred.

Figure 7 illustrates the relationship between the $b$-value and stress level for the specimens with orthogonal cracks. The stress level was defined as the ratio of the axial stress to uniaxial compressive strength. It can be seen that the $b$-value fluctuated but generally decreased. The $b$-values for the specimen with the main crack angles of $30^{\circ}$ and $60^{\circ}$ were relatively large while the $b$-values for the specimen with the main crack angles of 0 and $90^{\circ}$ were relatively small. Therefore, the $b$-value of failure precursor for the rock mass with joints parallel to the loading direction could be smaller. The critical $b$-value and the corresponding stress lever are listed in Table 2. It can be seen that the last dropping of the $b$ value started at the stress level of $0.85-0.94$ for the specimens with orthogonal cracks. And the smaller the critical $b$-value is, the larger the corresponding stress level is. Therefore, the smaller the critical $b$-value is, the sooner the final failure of rock will occur.

Digital image correlation (DIC) is an optical and noncontact deformation measurement technique for obtaining the surface strain filed [33-36]. The digital image processing (DIC) techniques were employed to analyze the cracking process and crack pattern of the specimens during the loading. Figure 8 shows the $b$-value and typical DIC images from the VIC-3D system. The contours are the maximum principal strains with values decreasing from the largest (red) to the smallest (blue). It can be seen that the cracking of specimens was directional and the crack patterns differed by the preexisting cracks. The load-induced cracks were mainly wing-cracks and anti-wing-cracks around the preexisting crack tip. The wing-crack is generated at the end of the preexisting crack and propagated in direction of the wingcrack of the preexisting crack; the anti-wing-crack is usually generated later than the wing-cracks and propagated in the opposite direction along the preexisting crack [5]. The crack patterns for the specimens 00-90 and 90-90 were similar, in 
which the crack was initiated at the preexisting crack tip and propagated towards the loading sides. The $b$-value dropped when the crack was initiated at the crack tip and propagated. Taking the specimen 90-90 as an example, the variation of $b$ value between the first and second DIC images was caused by the wing-crack propagation while the variation of $b$-value between the last two DIC images was caused by the antiwing-crack initiation and propagation. Moreover, the dropping of $b$-value always occurred before cracking which indicated that $b$-value could be a failure precursor for the rock with cracks.

\section{Conclusions}

In this paper, granite specimens were made with orthogonal cracks and used for uniaxial compression tests. The acoustic emission events and surface strain field data of the specimens during compressive loading were recorded. The axial stress, $b$ value, ring-down count of $\mathrm{AE}$, cumulative ring-down count of $\mathrm{AE}$, and fracture characteristics of the specimens were obtained and discussed. Conclusions can be given as follows:

(1) The granite specimens with orthogonal cracks underwent multiple cycles of energy accumulationrelease under the uniaxial compression. The AE can be classified as a quiet period and outbreak period during the compression tests. The specimens with orthogonal cracks stepwise cracked with the axial load increasing.

(2) For the specimens with orthogonal cracks, the $b$ value of $\mathrm{AE}$ was volatile but generally decreased until complete failure. The maximum $b$-value for the intact specimen was significantly larger than that for the specimens with two orthogonal cracks. The specimen with orthogonal cracks is more prone to initial cracking than the intact rock.

(3) With the angle $\alpha$ between the main crack and loading direction increasing, the uniaxial compressive strength and $b$-value of AE firstly increased and then decreased. At the elastic stage, the $b$-value experienced the cycles of "dropping, increasing, being stable, and redropping." The $b$-value could be a failure precursor for the rock with cracks and the critical $b$-values were about $0.63-1.24$ for the specimens with orthogonal cracks.

(4) The load-induced cracks were mainly wing-cracks and anti-wing-cracks around the preexisting crack tip. The crack patterns and $b$-values were affected by the main crack direction.

\section{Data Availability}

The experimental data used to support the findings of this study are included within the article.

\section{Conflicts of Interest}

The authors declare that there are no conflicts of interest regarding the publication of this paper.

\section{Acknowledgments}

This research was funded by the Fundamental Research Funds for the Central Universities (no. FRF-TP-18-015A3).

\section{References}

[1] Z. Y. Yang, J. M. Chen, and T. H. Huang, "Effect of joint sets on the strength and deformation of rock mass models," International Journal of Rock Mechanics and Mining Sciences, vol. 35, no. 1, pp. 75-84, 1998.

[2] R.-h. Cao, P. Cao, H. Lin, X. Fan, C. Zhang, and T. Liu, "Crack initiation, propagation, and failure characteristics of jointed rock or rock-like specimens: a review," Advances in Civil Engineering, vol. 2019, Article ID 6975751, 31 pages, 2019.

[3] M. Singh, K. S. Rao, and T. Ramamurthy, "Strength and deformational behaviour of a jointed rock mass," Rock Mechanics and Rock Engineering, vol. 35, no. 1, pp. 45-64, 2002.

[4] B. Tokhmechi, H. Memarian, B. Moshiri, V. Rasouli, and H. A. Noubari, "Investigating the validity of conventional joint set clustering methods," Engineering Geology, vol. 118, no. 3-4, pp. 75-81, 2011.

[5] H. Lee and S. Jeon, "An experimental and numerical study of fracture coalescence in pre-cracked specimens under uniaxial compression," International Journal of Solids and Structures, vol. 48, no. 6, pp. 979-999, 2011.

[6] A. Bobet and H. H. Einstein, "Fracture coalescence in rocktype materials under uniaxial and biaxial compression," International Journal of Rock Mechanics and Mining Sciences, vol. 35, no. 7, pp. 863-888, 1998.

[7] S. Q. Yang, D. S. Yang, H. W. Jing, Y. H. Li, and S. Y. Wang, "An experimental study of the fracture coalescence behaviour of brittle sandstone specimens containing three fissures," Rock Mechanics and Rock Engineering, vol. 45, no. 4, pp. 563-582, 2012.

[8] S.-Q. Yang, X.-R. Liu, and H.-W. Jing, "Experimental investigation on fracture coalescence behavior of red sandstone containing two unparallel fissures under uniaxial compression," International Journal of Rock Mechanics and Mining Sciences, vol. 63, no. 63, pp. 82-92, 2013.

[9] D. M. Ivars, M. E. Pierce, C. Darcel et al., "The synthetic rock mass approach for jointed rock mass modelling," International Journal of Rock Mechanics and Mining Sciences, vol. 48, no. 2, pp. 219-244, 2011.

[10] X. Wang, W. Yuan, Y. Yan et al., "Scale effect of mechanical properties of jointed rock mass: a numerical study based on particle flow code," Geomechanics and Engineering, vol. 21, no. 3, pp. 259-268, 2020.

[11] J. Wang, Y. Zhang, Z. Qin, S. Song, and P. Lin, "Analysis method of water inrush for tunnels with damaged waterresisting rock mass based on finite element method-smooth particle hydrodynamics coupling," Computers and Geotechnics, vol. 126, Article ID 103725, 2020.

[12] X. Xi, X. Wu, Q. Guo, and M. Cai, "Experimental investigation and numerical simulation on the crack initiation and propagation of rock with pre-existing cracks," IEEE Access, vol. 8, pp. 129636-129644, 2020.

[13] Q. Guo, J. Pan, M. Cai, and Y. Zhang, "Investigating the effect of rock bridge on the stability of locked section slopes by the direct shear test and acoustic emission technique," Sensors, vol. 20, no. 3, p. 638, 2020.

[14] X. Xi, S. Yang, and C.-Q. Li, “A non-uniform corrosion model and meso-scale fracture modelling of concrete," Cement and Concrete Research, vol. 108, pp. 87-102, 2018. 
[15] X. Xi, S. Yang, C.-Q. Li, M. Cai, X. Hu, and Z. K. Shipton, "Meso-scale mixed-mode fracture modelling of reinforced concrete structures subjected to non-uniform corrosion," Engineering Fracture Mechanics, vol. 199, pp. 114-130, 2018.

[16] G. Shi, X. Yang, H. Yu, and C. Zhu, "Acoustic emission characteristics of creep fracture evolution in double-fracture fine sandstone under uniaxial compression," Engineering Fracture Mechanics, vol. 210, pp. 13-28, 2019.

[17] P. Ganne, A. Vervoort, and M. Wevers, "Quantification of pre-peak brittle damage: correlation between acoustic emission and observed micro-fracturing," International Journal of Rock Mechanics and Mining Sciences, vol. 44, no. 5, pp. 720-729, 2007.

[18] E. Eberhardt, D. Stead, B. Stimpson, and R. S. Read, "Identifying crack initiation and propagation thresholds in brittle rock," Canadian Geotechnical Journal, vol. 35, no. 2, pp. 222-233, 1998.

[19] R. Zhang, H. P. Xie, J. F. Liu et al., "Experimental study on acoustic emission characteristics of rock failure under uniaxial multilevel loadings," Chinese Journal of Rock Mechanics and Engineering, vol. 25, no. 12, pp. 2584-2588, 2006.

[20] X. D. Zhao, Y. H. Li, R. F. Yuan, T. H. Yang, J. Y. Zhang, and J. P. Liu, "Study on crack dynamic propagation process of rock samples based on acoustic emission location," Chinese Journal of Rock Mechanics and Engineering, vol. 26, no. 5, pp. 944950, 2007.

[21] Y. H. Li, J. P. Liu, X. D. Zhao, and Y. J. Yang, "Study on $b$-value and fractal dimension of acoustic emission during rock failure process," Rock and Soil Mechanics, vol. 30, no. 9, pp. 2559$2563,2009$.

[22] Z. Zhang, R. Zhang, H. Xie, J. Liu, and P. Were, "Differences in the acoustic emission characteristics of rock salt compared with granite and marble during the damage evolution process," Environmental Earth Sciences, vol. 73, no. 11, pp. 6987-6999, 2015.

[23] X. Lai, J. Ren, F. Cui et al., "Study on vertical cross loading fracture of coal mass through hole based on AE-TF characteristics," Applied Acoustics, vol. 166, Article ID 107353, 2020.

[24] V. Rudajev, J. Vilhelm, and T. Lokajiček, "Laboratory studies of acoustic emission prior to uniaxial compressive rock failure," International Journal of Rock Mechanics and Mining Sciences, vol. 37, no. 4, pp. 699-704, 2000.

[25] Q. Meng, M. Zhang, L. Han, H. Pu, and T. Nie, "Effects of acoustic emission and energy evolution of rock specimens under the uniaxial cyclic loading and unloading compression," Rock Mechanics and Rock Engineering, vol. 49, no. 10, pp. 3873-3886, 2016.

[26] Q. Meng, M. Zhang, L. Han, H. Pu, and Y. Chen, "Acoustic emission characteristics of red sandstone specimens under uniaxial cyclic loading and unloading compression," Rock Mechanics and Rock Engineering, vol. 51, no. 4, pp. 969-988, 2018.

[27] S. B. Hu, J. Deng, C. D. Ma, and W. Wang, "Experimental study of failure characteristics of rock containing flaw under cycle loading," Chinese Journal of Rock Mechanics and Engineering, vol. 28, no. 12, pp. 2490-2495, 2009.

[28] Q. J. Zhou, T. C. Li, and B. N. Gong, "Experimental study on shear behaviors of brittle materials under cyclic loading," Chinese Journal of Rock Mechanics and Engineering, vol. 26, no. 3, pp. 573-579, 2007.

[29] D. Y. Liu, K. S. Zhu, and B. X. Hu, "A study on acoustic emission characters of failure of fissured rock on compression," Underground Space, vol. 18, no. 4, pp. 210-215, 1998.
[30] S. W. Bai, W. Z. Ren, D. X. Feng et al., "Failure mechanism and strength properties of rockmass containing close intermittent joints under plane stress condition," Chinese Journal of Rock Mechanics and Engineering, vol. 18, no. 6, pp. 635-640, 1999.

[31] B. Gutenberg and C. F. Richter, "Magnitude and energy of earthquakes," Annals of Geophysics, vol. 9, pp. 1-15, 1956.

[32] J. Žalohar, "Gutenberg-Richter's law," Developments in Structural Geology and Tectonics, vol. 2, pp. 173-178, 2018.

[33] S. Dai, X. Liu, and K. Nawnit, "Experimental study on the fracture process zone characteristics in concrete utilizing DIC and AE methods," Applied Sciences, vol. 9, no. 7, Article ID 1346, 2019.

[34] X. Wu, "Crack initiation and failure mechanism of granite with single crack," Geotechnical and Geological Engineering, vol. 38, no. 1, pp. 651-661, 2020.

[35] X. Wang, Z. Wen, Y. Jiang, and H. Huang, "Experimental study on mechanical and acoustic emission characteristics of rock-like material under non-uniformly distributed loads," Rock Mechanics and Rock Engineering, vol. 51, no. 3, pp. 729-745, 2018.

[36] P. T. Wang, Z. J. Huang, F. H. Ren et al., "Research on direct shear behaviour and fracture patterns of 3D-printed complex jointed rock models," Rock and Solid Mechanics, vol. 41, no. 1, pp. 46-56, 2020. 